\title{
A RELAÇÃO POLÊMICA ENTRE OS CONCEITOS DE SOLIDARIEDADE E COMPETITIVIDADE NA PRÁTICA DISCURSIVA SOBRE A RESPONSABILIDADE SOCIAL EMPRESARIAL
}

\section{THE POLEMIC RELATIONSHIP BETWEEN THE CONCEPTS OF SOLIDARITY AND COMPETITIVENESS IN THE DISCURSIVE PRACTICE ABOUT THE CORPORATE SOCIAL RESPONSIBILITY}

\author{
Laura Daniela Miranda de QUEIROZ ${ }^{1}$ \\ UFPA- Universidade Federal do Pará \\ Fátima Cristina da Costa PESSOA ${ }^{2}$ \\ UFPA- Universidade Federal do Pará
}

\begin{abstract}
RESUMO: Este artigo investiga as relações polêmicas (MAINGUENEAU, 1997; 2008) que constituem o discurso da responsabilidade social empresarial (RSE), reproduzidas na prática discursiva pedagógica conduzida nos manuais "Responsabilidade Social Empresarial para Micro e Pequenas Empresas - Passo a Passo" e "Indicadores Ethos-Sebrae de Responsabilidade Social Empresarial para Micro e Pequenas Empresas". Trata-se de manuais elaborados pelo Sebrae - Serviço Brasileiro de Apoio às Micro e Pequenas Empresas e pelo Instituto Ethos de Empresas e Responsabilidade Social e Empresarial com a finalidade de orientar micro e pequenos empresários a alinharem sua forma de gestão ao contexto da RSE. Parte-se da hipótese de que o entrelaçamento de formações discursivas conflitantes nesse espaço discursivo efetiva-se pela construção de um simulacro da noção de solidariedade, que passa a servir ao discurso da competitividade entre empresas. Entendese que o discurso da RSE produz uma cena enunciativa de equidade social, de ética nas relações de trabalho, de transparência na gestão das empresas, de uma postura dialógica entre os sujeitos que dividem o espaço de trabalho, que, no entanto, se apresenta como um mecanismo de conformação dos sujeitos exteriores à comunidade discursiva empresarial para que as condições de produção e de lucratividade das corporações não sejam ameaçadas.
\end{abstract}

PALAVRAS-CHAVE: Prática discursiva; Interdiscurso; Polêmica; Simulacro; Responsabilidade social empresarial.

ABSTRACT: This article investigates the polemic relationships (MAINGUENEAU, 1997, 2008) which constitute the discourse of corporate social responsibility and which are reproduced in the pedagogical discursive practice that is led by the manuals "Corporate Social Responsibility for Micro and Small Enterprises - Step by Step" and "Ethos Indicators - Sebrae of Corporate Social Responsibility for Micro and Small Enterprises". These manuals were elaborated by Sebrae - Brazilian Service of Support for Micro and Small Enterprises and by Ethos Institute of Business and Social Responsibility with the purpose of guiding micro and small entrepreneurs to align their management approach to the context of social responsibility. This study starts from the hypothesis that the

\footnotetext{
${ }^{1}$ Discente do Programa de Pós-Graduação em Letras da Universidade Federal do Pará.

${ }^{2}$ Professora Associada do Instituto de Letras e Comunicação da Universidade Federal do Pará. Docente Permanente do Programa de Pós-Graduação em Letras da Universidade Federal do Pará.
} 
intertwining of conflicting discursive formations in this discursive space" becomes effective by constructing a simulacrum of the notion of solidarity, which happens to serve the discourse of competitiveness among companies. This study understands that the discourse of social responsibility produces an enunciative scene of social equity, of ethics in labor relations, of transparency in corporate management, of a dialogical attitude among the subjects that divide the workspace, which, however, this discourse presents itself as a mechanism of resignation of the subject which are outside of the corporate discursive community for that the conditions of production and profitability of the corporations are not endangered.

KEYWORDS: Discursive practice; Interdiscourse; Polemic; Simulacrum; Corporate social responsibility.

\section{Introdução}

O percurso de pesquisa com base no qual se propõe este artigo constitui-se pelas reflexões acerca das relações que se estabelecem entre as práticas discursivas e as práticas de trabalho, investigando-se a reciprocidade entre o dizer e o fazer. Considera-se que as práticas discursivas são parte constituinte do processo que produz, organiza e valida ações nos espaços de trabalho, bem como parte do processo que forma sujeitos que atendam às exigências de sua execução. As especificidades dessas reflexões têm conduzido ao reconhecimento de que a construção de identidades e das relações entre os sujeitos do trabalho, assim como a regulação das ações de trabalho e a formação de saberes para o trabalho são processos constituídos no e pelo exercício enunciativo.

Reconhecendo-se, então, que as mudanças no sistema capitalista que interferem significativamente no modo de atuação no espaço do trabalho empresarial constituem-se também nas e pelas práticas discursivas nas organizações corporativas, este artigo se propõe a apresentar resultados preliminares de uma investigação em andamento sobre a prática pedagógica de orientação às micro e pequenas empresas (MPE) conduzida pelo Sebrae Serviço Brasileiro de Apoio às Micro e Pequenas Empresas ${ }^{3}$ e pelo Instituto Ethos de Empresas e Responsabilidade Social e Empresarial ${ }^{4}$ a respeito das ações que as MPE devem cultivar para se inserirem na atmosfera da responsabilidade social empresarial (RSE). Cesar (2008) desenvolveu uma pesquisa extensa sobre a emergência de práticas de intervenção social do empresariado no Brasil, num processo que a pesquisadora denominou como "desresponsabilização do estado" (CESAR, 2008, p. 17). Esse processo se caracteriza, segundo a autora, por uma redução da responsabilidade do Estado com as políticas sociais em prol de redes de solidariedade social que incluem fundações e institutos sociais, entidades filantrópicas, entidades religiosas, entidades de direitos civis, movimentos sociais, as quais se inserem no chamado terceiro setor.

Instituições como o Sebrae e o Instituto Ethos apresentam-se no cenário de atuação das MPE como espaços legítimos para oferecer orientações às empresas sobre o modo de adesão à ações de RSE por meio de um mecanismo estratégico para alavancar os resultados dos empreendimentos empresariais. Em dois manuais elaborados em parceria pelas duas instituições, intitulados "Responsabilidade Social Empresarial para Micro e Pequenas

\footnotetext{
${ }^{3}$ O Sebrae - Serviço Brasileiro de Apoio às Micro e Pequenas Empresas é uma entidade associativa de Direito Privado sem fins lucrativos, transformado em serviço social autônomo pelo Decreto $\mathrm{n}^{\circ} .99 .570$ de outubro de 1990.

${ }^{4}$ O Instituto Ethos de Empresas e Responsabilidade Social é uma organização sem fins lucrativos, caracterizada como Oscip (Organização da Sociedade Civil de Interesse Público) e criada em 1998 por um grupo de empresários da iniciativa privada que, por meio da organização, propuseram-se a orientar empresas a gerirem seus negócios sob a perspectiva da sustentabilidade.
} 
Empresas - Passo a Passo" (MD) ${ }^{5}$, publicado em 2003, e "Indicadores Ethos-Sebrae de Responsabilidade Social Empresarial para Micro e Pequenas Empresas” (MI) ${ }^{6}$, publicado em 2012, são prescritos modelos de práticas qualificadas como socialmente responsáveis. Verifica-se que as instituições responsáveis pela produção dos manuais reproduzem um discurso sugerindo que a adoção de ações solidárias pelas MPE permita a construção de uma imagem positiva das empresas em permanente competição pela preferência no mercado consumidor. Entende-se, então, que as práticas de responsabilidade social às quais as empresas devem aderir estão a serviço das exigências de competitividade entre elas, havendo na relação entre os discursos de solidariedade e de competitividade uma distorção que causa efeitos de sentido discutidos nesta pesquisa. Assim, busca-se investigar como se estabelecem as relações interdiscursivas constituintes do discurso da responsabilidade social empresarial, considerando-se que essa interação constitutiva entre discursos traduz-se num processo de interincompreensão (MAINGUENEAU, 2008).

Em uma primeira leitura dos documentos, observa-se que as duas instituições assumem a defesa do argumento de que a adoção de ações solidárias pelas MPE garante maior competitividade no mercado empresarial. O enunciado "Ser mais responsável socialmente é fator de competitividade", que intitula uma das subseções em que se divide a apresentação do $\mathrm{MD}$, aponta, na prática discursiva sobre a RSE, para a equivalência entre as noções de solidariedade e competividade, equivalência que pode ser questionada, considerando-se que as duas noções se constituem em formações discursivas antagônicas: a primeira que implica o cuidado com o outro, o compromisso com o outro, o respeito pelo outro; a segunda, uma desigualdade entre pares que buscam superar-se. Empresas competem em busca de destaque, o que significa que os objetivos e interesses do eu sobrepõem-se aos do outro. Se em uma relação de competitividade há uma tensão entre os envolvidos, postula-se que, na prática discursiva sobre a RSE, a conjugação da noção de solidariedade à noção de competitividade só pode se estabelecer por meio de um simulacro em torno da primeira noção. A hipótese que se investiga é que, no discurso da RSE, a tensão entre a noção de solidariedade e a noção de competitividade dissolve-se pelo deslocamento da noção de solidariedade, que passa a servir à competitividade das empresas.

Posto isso, para que o estudo possa dar conta da investigação sobre a complexidade em torno do funcionamento discursivo nos corpora selecionados para análise, toma-se como base os pressupostos teóricos e metodológicos da Análise do Discurso, considerando-se o discurso no âmbito das relações interdiscursivas e da constituição destas nos espaços institucionais. Os conceitos de prática discursiva, de interdiscurso e de polêmica postulados por Maingueneau $(1997$; 2008) dão suporte a uma investigação científica que busca compreender esse espaço de tensão. Com base nessa perspectiva, é imprescindível ao analista compreender o discurso enquanto constituinte identitário de um grupo social, como atividade humana que pressupõe a realidade da qual faz parte, sob uma perspectiva em que o interior e o exterior discursivos não podem ser vistos separadamente.

\section{As relações interdiscursivas nas práticas discursivas empresariais sobre a RSE}

\footnotetext{
${ }^{5} \mathrm{O}$ manual organiza-se em torno de sete diretrizes, considerados os temas em que se dividem as orientações sobre as ações de RSE no ambiente corporativo. Por essa razão, utiliza-se a sigla MD (Manual das Diretrizes) para identificar o documento ao longo do texto.

${ }^{6} \mathrm{O}$ manual organiza-se em torno de trinta e seis indicadores, agrupados em torno de sete temas, que servem à autoavaliação de micro e pequenos empresários no que se refere à incorporação de práticas de RSE na gestão de seus empreendimentos. Por essa razão, utiliza-se a sigla MI (Manual dos Indicadores) para identificar o documento ao longo do texto.
}

Disponível em: http://seer.fclar.unesp.br/casa 
Segundo os pressupostos teóricos de Maingueneau (1997; 2008), há uma relação constitutiva entre os grupos e os discursos por eles mobilizados. Elementos textuais e fenômenos sociais encontram-se entrelaçados como constituintes identitários dos discursos e das comunidades discursivas. É focalizando essa relação constitutiva que Maingueneau (1997, p. 56) postula o conceito de prática discursiva:

[...] falaremos de prática discursiva para designar esta reversibilidade essencial entre as duas faces, social e textual, do discurso. Assim procedendo, reformulamos um termo de Michel Foucault, que o utiliza para referir-se ao sistema que, no interior de uma formação discursiva dada, regula a dispersão dos lugares institucionais passíveis de serem ocupados por um sujeito de enunciação. Aqui ver-se-á, de preferência, um processo de organização que estrutura ao mesmo tempo as duas vertentes do discurso. A noção de "prática discursiva" integra, pois, estes dois elementos: por um lado, a formação discursiva, por outro, o que chamaremos de comunidade discursiva, isto é, o grupo ou a organização de grupos no interior dos quais são produzidos, gerados os textos que dependem da formação discursiva. (grifo do autor).

O discurso, enquanto prática, encontra-se entrelaçado ao seu espaço de produção e aos grupos que o compõe, sendo constituído, portanto, por um sistema de relações. Isso porque as maneiras pelas quais os grupos se organizam e os modos de agir que os caracterizam não estão separados de suas práticas discursivas. Como afirma Maingueneau (1997, p.60, grifo do autor), "o sujeito inscreve-se de maneira indissociável em processos de organização social e textual".

Ainda em Maingueneau (2008, p. 20), para o analista de discurso "a unidade de análise pertinente não é o discurso, mas um espaço de trocas entre vários discursos convenientemente escolhidos". Constitui-se, portanto, nesta investigação o espaço discursivo que "delimita um subconjunto do campo discursivo, ligando pelo menos duas formações discursivas que, supõe-se, mantêm relações privilegiadas, cruciais para a compreensão dos discursos considerados" (MAINGUENEAU, 1997, p. 117). O espaço discursivo recortado para esta pesquisa considera a formação discursiva (FD) da solidariedade e a da competitividade, formações discursivas entendidas em uma relação conflituosa. O conflito se constitui na e pela incompreensão de um discurso sobre o seu Outro, considerando-se que o sentido circula num nível dissimétrico de uma FD a outra de maneira que a interdiscursividade se estabelece num movimento que "funda um desentendimento recíproco" (MAINGUENEAU, 2008, p. 99). Na relação entre o exercício enunciativo e a ordem sóciohistórica no interior da qual se realiza, o domínio que permite ao enunciador situar-se na formação discursiva à qual suas práticas discursivas estão vinculadas relaciona-se a sua experiência enquanto membro de um grupo, enquanto membro de uma comunidade discursiva, isto é, "o grupo ou a organização de grupos no interior dos quais são produzidos, gerados os textos que dependem da formação discursiva" (MAINGUENEAU, 1997, p. 56). Isso porque, na perspectiva do autor:

A noção de comunidade discursiva é solidária à de formação discursiva [...]. Os modos de organização dos homens e de seus discursos são indissociáveis; as doutrinas são inseparáveis das instituições que as fazem emergirem e que as mantêm. Essa hipótese diz respeito, em primeiro lugar, aos grupos de produtores de textos, que não devem ser considerados como mediadores 
transparentes. Uma tal hipótese recusa toda interpretação ingênua da distinção entre "interior" e "exterior" de uma formação discursiva. Nessa perspectiva, a noção de comunidade discursiva permite, sobretudo, caracterizar os locutores, destacando posicionamentos (CHARAUDEAU; MAINGUENEAU, 2012, p. 110).

O processo de delimitação recíproca em que formações discursivas concorrem para requerer seu próprio espaço cria uma relação polêmica, na qual, segundo Maingueneau (2008, p. 21), cada "um conduz o Outro em seu fechamento, traduzindo seus enunciados nas categorias do Mesmo e, assim, sua relação com esse Outro se dá sob a forma do 'simulacro' que dele constrói”. No âmbito desta pesquisa, está-se diante de uma prática discursiva que articula formações discursivas antagônicas em uma relação polêmica: práticas de solidariedade, de ajuda mútua, de ética nas relações de trabalho são incentivadas para favorecer empresas a terem condições de competir entre si, processo no qual prevalece a desigualdade entre pares que buscam superar-se.

O conceito de polêmica, segundo Maingueneau (2008, p.21), "longe de ser o reencontro acidental de dois discursos que se teriam instituídos independentemente um do outro, é de fato a manifestação de uma incompatibilidade radical, a mesma que permitiu a constituição dos discursos". Entende-se, portanto, que o MD e o MI, ao defenderem que práticas socialmente responsáveis conduzem empresas ao sucesso nos negócios, inscrevem-se em uma formação discursiva que se constitui em torno da noção de competitividade, estabelecendo, no entanto, um entrelaçamento com a noção de solidariedade, noção reconstituída com base na rede de restrições semânticas ${ }^{7}$ dominante, o que gera uma relação de interincompreensão. Postula-se que nesse espaço discursivo as ações de solidariedade estão a serviço de interesses econômicos que visam ao sucesso individual, havendo nisso uma contradição.

Neste estudo pretende-se investigar como os discursos dialogam no contexto da RSE, considerando-se a comunidade discursiva e a maneira como as formações discursivas em torno da solidariedade e da competitividade se entrecruzam. Nesse sentido, conduz-se a investigação com base no postulado teórico de que as condições sócio-históricas agem coercitivamente sobre os grupos e sobre seus discursos. Sobre essa relação regulada Maingueneau destaca:

[...] é preciso articular as coerções que possibilitam a formação discursiva com as que possibilitam o grupo, já que estas duas instâncias são conduzidas pela mesma lógica. Não se dirá, pois, que o grupo gera um discurso do exterior, mas que a instituição discursiva possui, de alguma forma, duas faces, uma que diz respeito ao social e a outra, a linguagem. A partir daí, as formações discursivas concorrentes em uma determinada área também se põem pelo modo de funcionamento dos grupos que lhes estão associados (MAINGUENEAU, 1997, p.55, grifo do autor).

Os dados que serão discutidos neste artigo fazem parte de um percurso analítico que busca compreender o modo como se constitui, conforme a hipótese inicial, o simulacro da noção de solidariedade na prática pedagógica produzida pela e destinada à comunidade

\footnotetext{
${ }^{7}$ Entende-se por rede de restrições semânticas, conforme Maingueneau (2008), "um filtro que fixa os critérios em virtude dos quais certos textos se distinguem do conjunto dos textos possíveis como pertencendo a uma formação discursiva determinada" (MAINGUENEAU, 2008, p. 49).
} 
empresarial, uma vez que se acredita, conforme já enunciado, que a tensão entre solidariedade e competitividade, no discurso da RSE, dissolve-se pelo deslocamento da noção de solidariedade, que passa a servir à competitividade.

\section{A emergência e a difusão do discurso da RSE no espaço empresarial brasileiro}

Considera-se, no âmbito desta pesquisa, o MD e o MI documentos que revelam os posicionamentos hegemônicos no campo empresarial sobre a importância das MPE aderirem a práticas caracterizadas como socialmente responsáveis. O Sebrae - Serviço Brasileiro de Apoio às Micro e Pequenas Empresas e o Instituto Ethos de Empresas e Responsabilidade Social e Empresarial são instituições que se apresentam nesse contexto como espaços legítimos de aconselhamento ao micro e pequeno empresariado na gestão dos seus negócios, de tal maneira que se reconhece nos documentos elaborados uma finalidade pedagógica. Neles são prescritas ações atestadas como mecanismos eficazes e necessários para o bom desempenho das empresas no mercado consumidor. Assim, retomando-se a noção de prática discursiva proposta por Maingueneau (1997), é importante pontuar que os manuais enquanto práticas discursivas constituem uma noção de trabalho idealizada para responder às demandas que o mercado capitalista determina.

Os textos analisados neste artigo apontam para uma regularidade nos discursos que legitimam a RSE, discurso que se constitui pelo entrecruzamento de formações discursivas antagônicas, as quais se fundam nos conceitos de solidariedade e de competitividade. Essa relação constitutiva gera efeitos de sentido que levam ao desdobramento de representações positivas, mas ao mesmo tempo distorcidas, sobre as empresas que seguem as propostas sustentadas em um projeto de empresa cidadã.

Para compreender como essas relações interdiscursivas se estabelecem, convém mencionar um dos postulados de Maingueneau (2008, p. 106, grifo do autor) sobre formação discursiva, segundo o qual a FD "não define somente um universo de sentido próprio, ela define igualmente seu modo de coexistência com os outros". Assim, na constituição da prática discursiva empresarial sobre a responsabilidade social identificam-se noções que coexistem, como transparência, ética, solidariedade, competitividade, tratadas no manual em um nível de equivalência. Compreender a emergência desse discurso sobre a importância do desenvolvimento social promovido pelas empresas é um percurso importante para o que se pretende investigar neste trabalho.

Segundo Cesar (2008), no decorrer dos anos 1990, houve uma intensificação de programas de caráter educativo e assistencial implementados por empresas que visam à aproximação das mesmas com as comunidades locais. Diversas ações de intervenção social passaram a ser empreendidas pelas empresas e expostas em manuais, revistas de circulação interna, em campanhas publicitárias, com vistas a conferir aos empreendimentos uma imagem positiva. Nesse cenário emergem críticas, em grande parte do empresariado, sobre a ausência do Estado:

$\mathrm{Na}$ literatura empresarial existente sobre o tema da responsabilidade social, em geral acrítica e apologética, é recorrente a ideia de que, diante da incompetência do Estado na busca de soluções inovadoras para os problemas sociais, os empresários, mais confiantes em suas capacidades de decisão e ação, chamaram para si o exercício da responsabilidade social. Nessa perspectiva, o Estado aparece como malfeitor e culpado pela destruição dos alicerces econômicos (CESAR, 2008, p. 23). 
O Estado é visto como incompetente e incapaz de gerir as políticas sociais. Diante dessa situação o empresariado se veria forçado a desenvolver ações de responsabilidade social e, segundo Cesar (2008), desse cenário emerge a "empresa cidadã". A defesa dessa inserção das empresas no cenário de atuação político-social do Estado se dá por meio de um discurso que aponta para a possibilidade da conjugação harmônica entre as relações de produção impostas aos sujeitos do trabalho e o atendimento de suas necessidades e das necessidades das comunidades em seu entorno, de modo que não comprometa o crescimento econômico tampouco o desenvolvimento social:

E exatamente porque é preciso produzir para vender, ou prestar um verdadeiro serviço de utilidade coletiva para a sociedade, que a empresa deve pôr atenção nessa dupla realidade social de suas forças produtivas. Vamos ainda mais longe: numa economia concorrencial de mercado onde os meios da tecnologia, das finanças, e da comunicação levam a uma neutralização muito rápida da vantagem concorrencial fundada na exploração de uma abertura, o controle dos canais específicos de seu desenvolvimento social podem tornar-se a verdadeira vantagem competitiva da empresa. A qualidade de uma sociedade de produção, levando coordenação, solidariedade e criatividade entre seus atores, constitui, de fato, uma riqueza que não se rouba, nem se copia, nem se exporta (SAUNSALIEU; KIRSCHENER, 2006, p. 27).

Imersas em uma nova ordem socioeconômica, as empresas se organizariam e estabeleceriam novas relações de trabalho e de produção, com vistas a ampliar seu espaço de atuação e seu mercado consumidor. Nessa nova ordem que reestrutura a sociedade como um constituinte de todo o processo de produção, a racionalidade empresarial passa a incorporar em seus projetos ações de solidariedade que se propõem a dirimir ou a combater problemas sociais. Todavia, a tensão que se estabelece entre os polos de desenvolvimento econômico e de desenvolvimento social não se dissolve nos gestos de leitura de comunidades discursivas que geram e consomem esses textos e esse envolvimento social das empresas aparece em outro espaço e tempo mais a serviço de interesses que favoreçam o espaço econômico ocupado por elas do que a serviço da solução de problemas sociais. A esse respeito Kameyan (2000 apud CESAR, 2008, p. 30) afirma que as ações de responsabilidade social são um meio "de camuflar as novas estratégias de exploração, negando as contradições, na medida em que a consciência e a sociabilidade que se constroem na esfera da produção deslocam-se para a esfera da reprodução ou do consumo". Em torno dessas esferas cria-se um cenário de equidade como se todos os sujeitos estivessem em comum acordo quanto aos serviços oferecidos pelas empresas, as quais não seriam mais vilãs na relação com os funcionários, na degradação ambiental, no descaso quanto à qualidade de produtos e serviços, ao contrário, as empresas apresentam-se como responsáveis e abertas ao diálogo.

Outra forma de legitimidade do papel social dos empresários se dá, segundo Cesar (2008), pelo destaque que o empresariado tem nas ações de natureza política, seja pelo apoio a partidos ou pela disputa de postos legislativos. Com essa articulação entre as esferas públicas e privadas, o empresariado busca "homogeneizar suas propostas e redefinir o seu papel no processo de desenvolvimento do país, voltando-se para o debate sobre questões de interesse mais amplo, na tentativa de tornar as suas aspirações as das outras classes" (CESAR, 2008, p. 233). Como já foi dito, entende-se que essa tentativa de homogeneização induz a uma correspondência forçada entre solidariedade e competitividade, como se ambas proviessem do mesmo espaço discursivo, apagando-se a dissimetria entre os conceitos. Esse processo 
constitui uma distorção em torno da noção de solidariedade, como aponta a afirmação de Cesar (2008, p. 310-311):

\begin{abstract}
A responsabilidade social das empresas cumpre um papel ideológico funcional aos interesses do capital, contribuindo para promover o desmonte do estado e a reversão dos direitos sociais, materializados por meio das políticas e financiados por um sistema de solidariedade universal compulsória. Mistificando e encobrindo o real, o ideário da "empresa socialmente responsável" adensa a proposta de um outro padrão de intervenção nas expressões da questão social, com base nos valores de uma cidadania genérica, apolítica e a-histórica, que se sustenta na suposta "solidariedade comunitária" e na propalada assimetria entre eficiência pública e privada (CESAR, 2008, p. 310-311).
\end{abstract}

$\mathrm{Na}$ análise dos textos de apresentação do MD e do MI e na análise dos textos referentes às duas primeiras diretrizes e aos dois primeiros indicadores que compõem os manuais, buscar-se-á identificar os traços indiciários da relação polêmica entre as FD da solidariedade e da competitividade. Com base na perspectiva discursiva que orienta este percurso analítico, entende-se que na materialidade textual estão inscritos os traços que indicam o funcionamento discursivo tanto na ordem da enunciação quanto na ordem da organização social que a determina e por ela é determinada. Por essa razão é que pela análise dos recortes textuais que neste artigo serão apresentados entende-se que é possível reconhecer as relações interdiscursivas constituintes da polêmica sob análise, os simulacros advindos dessas relações e o perfil das comunidades discursivas implicadas nessa prática discursiva.

\title{
3 A prática discursiva empresarial sobre ações de responsabilidade social: a apresentação dos manuais
}

Os manuais Responsabilidade Social Empresarial para Micro e Pequenas Empresas - Passo a Passo (2003) e Indicadores Ethos-Sebrae de Responsabilidade Social Empresarial para Micro e Pequenas Empresas (2012) têm uma finalidade pedagógica: o primeiro de orientação; o segundo de avaliação. Trata-se de documentos produzidos por empresários e para empresários, nos quais são prescritas ações atestadas como mecanismos eficazes e necessários para o bom desempenho das empresas no mercado consumidor por meio da adesão às ações de RSE.

O MD organiza-se em três partes, distribuídas entre as suas setenta páginas. A primeira parte compreende a "Apresentação". Na segunda parte, abordam-se "As Sete Diretrizes da Responsabilidade Social Empresarial". Na terceira parte, discutem-se as "Novas exigências e Novas oportunidades" do mundo dos negócios. O MI organiza-se em duas partes, distribuídas entre as suas cinquenta e quatro páginas. A primeira parte compreende a "Apresentação". Na segunda parte, abordam-se os "Indicadores Ethos-Sebrae de Responsabilidade Social Empresarial para Micro e Pequenas Empresas".

Os dois documentos foram elaborados em momentos distintos, mas as propostas se articulam e se atualizam no tempo-espaço histórico e social. Tais propostas se inscrevem numa FD socioeconômica capitalista, para a qual o sucesso das empresas implica o reconhecimento do público consumidor como valor simbólico desejável para o empreendedor e, consequentemente, o lucro financeiro resultante das relações bem sucedidas estabelecidas no mercado. 
As sete diretrizes da responsabilidade social, segundo informações do MD, têm relação direta com os indicadores de RSE. Os dois manuais dialogam, considerando-se que o MI seria um instrumento de avaliação das empresas sobre seu envolvimento com os indicadores que são propostos em forma de diretrizes no MD. Investigar os dois documentos conjuntamente permite, então, considerar um escopo mais amplo da prática pedagógica orientada para as MPE. Nessa perspectiva, os manuais, enquanto prática discursiva engendrada no seio de relações sociais específicas, compõem corpora relevantes para o estudo que se pretende desenvolver, uma vez que se constitui numa forma de ação sobre o outro por meio da linguagem, na medida em que apresenta um conjunto de ações prescritas e um conjunto de instrumentos de regulação sobre a adesão a essas ações a serviço de um projeto de sociedade.

Inicia-se esse percurso analítico, destacando-se a cronografia discursiva ${ }^{8}$ que se institui no e pelo discurso da RSE para as ações empresariais, na seção de apresentação do MD:

(1MD) - A Responsabilidade Social Empresarial (RSE) tornou-se um fator de competitividade para os negócios. No passado, o que identificava uma empresa competitiva era basicamente o preço de seus produtos. Depois, veio a onda da qualidade, mas ainda focada nos produtos e serviços. Hoje, as empresas devem investir no permanente aperfeiçoamento de suas relações com todos os públicos dos quais dependem e com os quais se relacionam: clientes, fornecedores, empregados, parceiros e colaboradores. Isso inclui também a comunidade na qual atua, o governo, sem perder de vista a sociedade em geral, que construímos a cada dia (SEBRAE; INSTITUTO ETHOS, 2003, p. 06).

Conforme o dito, a noção de solidariedade é incorporada a posteriori ao discurso da competitividade, característico das ações empresariais, e essa incorporação se efetiva como um reforço que garante as condições de competitividade das empresas que não conseguem mais se manter atuantes no mercado apenas monitorando o preço e a qualidade dos seus produtos e serviços. Na cena de enunciação que se constitui, institui-se um novo tempo sociohistórico de atuação das empresas, o qual impõe um distanciamento entre presente e passado, caracterizando as ações realizadas no momento histórico atual como um diferencial para a empresa que adere às ações de RSE. Postula-se que, se a noção de solidariedade agrega-se ao discurso da competitividade para reforçá-lo, essa noção passa a significar em consonância com a rede de restrições semânticas que rege esse discurso. Embora a inserção de um novo conceito na ordem do discurso da competitividade possa alterar as relações no conjunto de uma FD, entende-se que, para que sejam reforçados os princípios e os valores da comunidade discursiva que o documento implica, é necessário que esse conceito seja incorporado a essa ordem discursiva na forma de um simulacro. Busca-se compreender, então, o que significa ser solidário no discurso da RSE.

Outro trecho da apresentação do MD que defende a adesão a práticas de RSE como mecanismo de garantia da competitividade das empresas é o que segue:

\footnotetext{
${ }^{8}$ Entende-se por cronografia discursiva, conforme Maingueneau (1997), um dos elementos constituintes da cena de enunciação que se refere ao "universo de sentido que uma formação discursiva constrói através de sua enunciação" (MAINGUENEAU, 1997, p. 41). Constituem a cena de enunciação também o locutor e o destinatário discursivos e a topografia discursiva.
} 


\begin{abstract}
(2MD) - Pelo retorno que traz - em termos de reconhecimento (imagem) e melhores condições de competir no mercado, além de contribuir substancialmente para o futuro do país -, o movimento da Responsabilidade Social Empresarial vem crescendo muito no Brasil. Já é significativo o número de grandes e médias empresas que selecionam fornecedores (micro e pequenos) utilizando critérios da RSE nos negócios. Também no acesso aos créditos e financiamentos é crescente a incorporação de critérios de gestão responsável (SEBRAE; INSTITUTO ETHOS, 2003, p. 06).
\end{abstract}

De acordo com o trecho destacado, as ações de RSE são qualificadas pelos benefícios que proporcionam às empresas e pelos benefícios que proporcionam àqueles que são alvo das ações de RSE. Enuncia-se de um lugar em que se postula haver uma conjunção harmônica entre os interesses empresariais e as ações responsáveis/solidárias destinadas ao público interno e externo das empresas. A relação de conjunção marcada pelo conectivo "além de" silencia toda e qualquer possibilidade de conflito entre os interesses das empresas e os interesses de seus empregados e de seu público alvo. Desse lugar de enunciação, a adoção de ações de RSE permite à comunidade empresarial ocupar-se das necessidades do outro sem que haja interferências no atendimento de suas próprias necessidades, uma vez que os interesses do Eu e do Outro são consideradas conciliáveis. Todavia, a forma de organização material do enunciado em destaque focaliza justamente os benefícios que a empresa alcançará com o investimento em ações de RSE, indício de que a hipótese incialmente formulada na condução desta pesquisa pode se confirmar: no discurso da RSE, os objetivos e interesses do eu sobrepõem-se aos do outro. Logo, a tensão entre a noção de solidariedade e a noção de competitividade dissolve-se pelo deslocamento da noção de solidariedade, que passa a servir à competitividade das empresas. Acredita-se que o documento ainda possa revelar, por meio da organização de sua forma material, os deslocamentos que sofre esse conceito e os contornos de seu simulacro no campo empresarial.

Inscrito na mesma FD, o MI reforça a cronografia discursiva do novo tempo para as empresas e a topografia discursiva de o espaço corporativo tornar-se o lugar de conciliação de interesses capitalistas e de interesses relativos ao atendimento das necessidades básicas dos cidadãos:

(3MI) - Os empresários de micro e pequenas empresas, por sua vez, têm demonstrado que podem responder com ações efetivas às novas exigências e necessidades do mercado. É crescente entre esses empreendedores a consciência de que a gestão socialmente responsável é a nova maneira de gerenciar os negócios e de tomar decisões, o que certamente contribuirá para a disseminação de novos valores para a sociedade, a promoção da eqüidade social e da sustentabilidade ambiental e a construção de um país melhor (SEBRAE; INSTITUTO ETHOS, 2012, p. 04 grifo nosso).

A apresentação do MI constitui-se ainda de um questionário inicial por meio do qual o Sebrae e o Instituto Ethos acreditam que podem auxiliar as MPE a reconhecerem o quanto estão preparadas para implementarem as ações de RSE. Esse questionário organiza-se em nove questões objetivas e cada uma constitui-se de três opções. A maneira como essas opções estão dispostas no questionário varia de um desconhecimento sobre o tema da RSE para um suposto cenário em que as MPE estariam alinhadas ao novo tempo da gestão empresarial:

(4MI) - Se para todas as questões você respondeu a letra "c", sua empresa e você já caminharam bastante na trilha da responsabilidade empresarial Disponível em: http://seer.fclar.unesp.br/casa 
(talvez você nem soubesse ...), e esse instrumento vai ajudá-lo a encurtar esse caminho. Se você respondeu com as letras "a" e "b", mas gostaria de ter respondido com a letra "c", você já está refletindo sobre a RSE, e esses indicadores poderão auxiliá-los a encontrar os meios para lidar com esse tema. Porém, se você acredita firmemente que a letra "a" é sempre a melhor resposta, recomendamos que você, além de responder às questões a seguir, informe-se sobre o novo contexto do mundo dos negócios no qual estamos inseridos. (SEBRAE; INSTITUTO ETHOS, 2012, p. 07).

A composição do questionário indica a existência de uma realidade não desejável, em que o empresário autodeclara-se alheio ao movimento amplamente defendido por Sebrae e Instituto Ethos, e de outra desejável, em que a empresa estaria preocupada com ações para o bem social e com a mudança nas relações econômicas, apontada pelas instituições autoras dos manuais:

(5MI) - Sobre responsabilidade social empresarial:

a. É o primeiro contato que tenho com esse tema.

b. Tenho poucos conhecimentos.

c. Estou buscando ampliar os conhecimentos que tenho. (SEBRAE; INSTITUTO ETHOS, 2012, p. 06).

Essa dissimetria estratégica entre as alternativas é indício da prática pedagógica em que se constituem os manuais que orientam as MPE sobre as ações de RSE. Nessa prática discursiva, constituem-se diferentes perfis de sujeitos do espaço de trabalho: aqueles que se alinham ao modelo hegemônico de como agir na gestão de seus negócios e aqueles que ainda não estão alinhados a esse modelo hegemônico. Na cena de enunciação constituída nos manuais, consolida-se a forma de organização de uma comunidade discursiva que deve agir em consonância e deve cuidar para que essa coesão seja mantida. Os sujeitos do trabalho que já compõem a comunidade discursiva que produz e consome esse discurso encontram nas instituições conselheiras o apoio necessário para a realização do trabalho com a promessa de alcançar maior eficiência; os sujeitos do trabalho que ainda destoam desse conjunto encontram nas instituições conselheiras as orientações necessárias para ajustar-se a ele, uma vez que não há alternativas para as ações de gestão empresarial. Esse funcionamento discursivo característico da atividade empresarial ilustra o postulado que Maingueneau (1997) evoca sobre a teoria do discurso: "Isto equivale a dizer que a teoria do discurso não é uma teoria do sujeito antes que este enuncie, mas uma teoria da instância de enunciação que é, ao mesmo tempo e intrinsecamente, um efeito de enunciado". (PARRET, 1983 apud MAINGUENEAU, 1997, p. 33).

A prática discursiva sobre a RSE é, portanto, produzida por empresários para empresários, isto é, uma comunidade discursiva hermética, que, no entanto, propõe ações direcionadas a sujeitos que estão no exterior dessa comunidade discursiva. Trata-se de investigar, nas orientações que as instituições direcionam às MPE, que lugares estão reservados a esses sujeitos externos no discurso da RSE e qual o simulacro da noção de solidariedade constitui-se na FD dominante centrada na noção de competitividade.

\section{A prática discursiva empresarial sobre ações de responsabilidade social: a constituição de simulacros}


Na segunda parte do MD, conforme já explicitado, reúnem-se as sete diretrizes em torno das quais as orientações para a adoção de ações de RSE serão apresentadas passo a passo. Também na segunda parte do MI reúnem-se os indicadores em torno dos quais será proposta a avaliação das formas de adoção de ações de RSE pelo micro e pequeno empresariado.

Em relação ao MD, todas as diretrizes são introduzidas por meio de verbos no modo imperativo, mais um indício na materialidade linguística que ratifica a percepção de que o documento em tela integra uma prática discursiva pedagógica, produzida por empresários e destinada a empresários. A primeira delas assim se apresenta: "(6MD) - "Adote valores e trabalhe com transparência”. (SEBRAE; INSTITUTO ETHOS, 2003, p. 13 grifo nosso).

Os enunciados que compõem essa segunda parte do MD indicam atitudes a adotar e são direcionados a um interlocutor interpelado permanentemente, como no excerto: "(7MD) Passo a passo: o que você pode fazer a partir de hoje em sua empresa para eleger e respeitar valores e agir com transparência". (SEBRAE; INSTITUTO ETHOS, 2003, p. 13).

Essa primeira diretriz destaca dois conceitos centrais no discurso da RSE: valores e transparência. Os valores estão relacionados à definição de uma missão para as empresas, que deverá ser expressa em termos de metas e aspirações que levem em consideração os públicos interno e externo com os quais as empresas se relacionam, bem como o reconhecimento e a divulgação dos itens da Declaração Universal dos Direitos Humanos que sejam relevantes para a área empresarial. As atitudes transparentes definem-se em termos de adoção de valores éticos, que deverão nortear as condutas e as decisões cotidianas das empresas, bem como a criação de um ambiente de trabalho propício ao diálogo, à escuta do outro. No entanto, embora a direção estabelecida para a condução dos empreendimentos seja a da atitude coletiva e colaborativa, portanto solidária, as ações pontuadas no documento revelam uma relação predominantemente hierárquica entre os sujeitos do ambiente empresarial, como expressa o seguinte trecho do MD:

(8MD) - Esteja disponível para dar esclarecimentos e aberto para ouvir diferentes opiniões. Comunique com clareza as decisões e procure explicar como elas são condizentes com os valores éticos da empresa, já que decorrem não apenas dos aspectos financeiros do negócio. Esclareça os funcionários sobre a responsabilidade que têm não só pela execução de suas atribuições, mas igualmente pela prática dos princípios adotados pela empresa. Encoraje-os a consultar um superior sempre que lhes ocorrer qualquer preocupação de ordem ética. (SEBRAE; INSTITUTO ETHOS, 2003, p.16).

No trecho destacado, verbos como "comunicar", "esclarecer", "encorajar", utilizados para definir a relação entre empregadores e empregados, não expressam com clareza o perfil de uma gestão colaborativa. Percebe-se na construção do texto que se propõe a orientar sobre a primeira diretriz da RSE uma tensão entre uma gestão solidária entre os empresários, funcionários e colaboradores e uma gestão impositiva e hierárquica. Se por um lado há no MD a sugestão de que a declaração de missão de uma empresa seja elaborada em conjunto com funcionários e colaboradores, por outro lado essa orientação não é apresentada de modo seguro, como outras ações pontuadas nessa prática pedagógica. No trecho a seguir, a 
orientação que aponta para uma atitude solidária no interior da empresa é apresentada de forma lacunar, por meio de uma locução verbal constituída por um modalizador deôntico ${ }^{9}$ :

(9MD) - Procure envolver funcionários e colaboradores na definição de missão que sua empresa vai adotar. Depois de pronta, reúna seu pessoal para uma conversa sobre a missão que a empresa se propôs a cumprir. Por fim transcreva-a num quadro, para que fique permanentemente exposta em lugar de destaque na empresa. Se sentir necessidade, revise periodicamente a missão de seu empreendimento. (SEBRAE; INSTITUTO ETHOS, 2003, p.13, grifo nosso).

Além de modalizar a ação que aponta para uma atitude solidária na condução das atividades empresariais, retirando desse enunciado em particular a força de ordem marcada nas construções imperativas sem modalização que predominam em outros enunciados do documento, no trecho em destaque observa-se também a orientação para uma atitude não colaborativa na ação de revisar a missão definida para o empreendimento. Esses indícios apontam o modo ambíguo como o empregado é chamado a ocupar o seu lugar em uma gestão colaborativa: a participação na definição de uma missão e de valores para o empreendimento é incentivada, mas ao mesmo tempo controlada por um superior.

No MI, o primeiro tema, "Valores, Transparência e Governança", é aquele relacionado à primeira diretriz no MD. Esse primeiro tema compõe-se de cinco indicadores: compromissos éticos, práticas antipropinas, práticas anticorrupção, balanço social e governança corporativa. Cada um deles tem início com uma pergunta principal que se desdobra em um conjunto de outras perguntas que se propõem a aprofundar a questão inicial e, segundo o documento, "contribuem para a compreensão de quais práticas devem ser incorporadas à gestão dos negócios" (SEBRAE; INSTITUTO ETHOS, 2012, p. 09). No conjunto dos indicadores do tema que inaugura o processo de autoavaliação das MPE, as perguntas que são pontos de partida referem-se à existência de documentos nas empresas que orientam a conduta dos sujeitos do trabalho, como o exemplo a seguir: "(10MI) - A empresa possui documento escrito que esclarece quais são os comportamentos incentivados por ela no que se refere às relações pessoais e comerciais?". (SEBRAE; INSTITUTO ETHOS, 2012, p. 16).

As perguntas subsequentes, em geral, buscam verificar se esses documentos são acessíveis a empregados, clientes, fornecedores e à comunidade. Há apenas uma pergunta que se refere à elaboração e à revisão do documento, questionando se há o envolvimento dos diferentes sujeitos do trabalho nessas ações. Chama a atenção o fato de que essa questão é tratada em termos de quantidade e não de representatividade dos sujeitos do trabalho: "(11MI) - Indicar o número de partes interessadas envolvidas na elaboração e revisão do documento (empregados, comunidade, fornecedores, clientes, governo)". (SEBRAE; INSTITUTO ETHOS, 2012, p. 16).

Em relação ao indicador sobre o balanço social da empresa, verifica-se novamente que as questões dizem respeito à necessidade de elaboração do documento pela empresa e à necessidade de esse documento estar acessível para os sujeitos do trabalho e para a comunidade com a qual a empresa se relaciona.

\footnotetext{
${ }^{9}$ Segundo Bronckart (1999), “as modalizações deônticas consistem em uma avaliação de alguns elementos do conteúdo temático, apoiada nos valores, nas opiniões e nas regras constitutivas do mundo social, apresentando os elementos do conteúdo como sendo do domínio do direito, da obrigação social e/ou da conformidade com as normas em uso" (BRONCKART, 1999, p. 331).
} 
(12MI) - A empresa tem informações sobre balanço social?

A empresa acredita que o balanço social pode ajudá-la a medir o impacto de suas operações sobre as pessoas e o meio ambiente e a divulgar seus compromissos futuros em relação a esses temas?

A empresa elabora seu balanço social?

A empresa divulga seu balanço social (em murais, locais de grande circulação, jornal do bairro etc.) para: seu público interno? Seus consumidores e clientes? Seus fornecedores? A comunidade de entorno? (SEBRAE; INSTITUTO ETHOS, 2012, p. 19).

Segundo fonte indicada no próprio manual ${ }^{10}$, o balanço social de uma empresa tem a função de tornar pública a responsabilidade social empresarial, construindo maiores vínculos entre a empresa, a sociedade e o meio ambiente. Verifica-se, desse modo, que há um silenciamento sobre a natureza e as formas de gestão alinhadas aos princípios da RSE. A discussão para a qual se orienta o micro e pequeno empresariado é a respeito da visibilidade que as empresas têm garantido a essas ações.

Na segunda diretriz do MD, intitulada "Valorize empregados e colaboradores", as questões voltam-se para as relações entre empresas e seu público interno: "(13MD) - Passo a passo: o que você pode fazer de agora em diante pelo público interno de sua empresa". (SEBRAE; INSTITUTO ETHOS, 2003, p.17).

Embora o documento oriente o empresariado para o "aperfeiçoamento das relações empregado-empresa" (SEBRAE; INSTITUTO ETHOS, 2003, p.17), reconhece-se na materialidade do enunciado uma direção descendente na relação entre esses sujeitos do trabalho: o empresário pode fazer alguma coisa por seus funcionários. Não se dá destaque a uma relação circular, portanto mais solidária, entre empresários e funcionários, no sentido de que o diálogo possa se estabelecer entre um polo e outro do espaço empresarial.

Mais uma vez, constitui-se a cena enunciativa que aponta para uma relação harmônica entre os sujeitos do espaço empresarial: "(14MD) - Empresas que valorizam seus funcionários valorizam, na verdade, a si mesmas”. (SEBRAE; INSTITUTO ETHOS, 2003, p. 17).

A topografia discursiva que se constitui na e pela enunciação é marcada pela harmonia, pela conciliação de interesses, pela equivalência entre os sujeitos que ocupam os diferentes lugares do espaço empresarial. Pode-se afirmar também que nessa topografia discursiva, para se constituir o espaço da conciliação harmônica entre os sujeitos do trabalho, silencia-se sobre os conflitos que historicamente caracterizam a relação entre empregadores e empregados e sobre a impossibilidade de conciliar em sua totalidade os interesses dessas distintas e desiguais posições sócio-históricas. Se as posições são distintas e desiguais, as diferenças deveriam se tornar visíveis em uma forma de gestão solidária. Somente em uma forma de gestão impositiva pode-se arbitrariamente silenciar as vozes de alguns sujeitos do espaço de trabalho empresarial em favor de uma imagem harmoniosa das relações de trabalho. Sobre esse aspecto da RSE, Cesar (2008, p. 250-251) declara:

Cabe ressaltar também que para as empresas a "responsabilidade social" também abarca as iniciativas voltadas para a força de trabalho contratada, postulando a melhoria da qualidade, da produtividade e da parceria entre capital e trabalho. A propagação da participação e da parceria, como forma de conjugar interesses e atenuar conflitos, bem como a crescente intervenção

${ }^{10}$ <www.balancosocial.org.br>. Acesso em: 10 set. 2013. 
empresarial no âmbito da qualificação e da esfera da reprodução material da força do trabalho, delineia uma busca à adesão do trabalhador às novas necessidades das empresas, sob os preceitos de uma outra política de produção.

O conflito latente e incontornável que caracteriza a relação entre empregadores e empregados se impõem no MD pelas fissuras de um dizer que tenta controlar o sentido na direção de uma cena enunciativa harmoniosa. Ao lado de enunciados que encenam o espaço solidário nas empresas, como "Crie um ambiente de trabalho que incentive os funcionários a trazer nova idéias e opiniões sobre a empresa." (SEBRAE; INSTITUTO ETHOS, 2003, p.17) e "Demonstre sempre que os comentários e sugestões são importantes na melhoria do desempenho da empresa como um todo." (SEBRAE; INSTITUTO ETHOS, 2003, p.17), há enunciados que são marcados por uma modalização deôntica quando se referem a ações que impliquem a concessão de direitos para o empregado:

(15MD) - Sendo possível, autorize o funcionário a realizar cursos durante o horário de trabalho ou subsidie os custos de cursos profissionalizantes (SEBRAE; INSTITUTO ETHOS, 2003, p.18, grifo nosso).

(16MD) - Havendo condições, conceda uma gratificação ou qualquer outra recompensa para aqueles que obtiverem certificação, graduação ou atingirem qualquer outro objetivo educacional (SEBRAE; INSTITUTO ETHOS, 2003, p.18, grifo nosso).

No polo da autoavaliação da prática pedagógica da comunidade empresarial, os oito indicadores relacionados ao público interno das MPE dizem respeito às condições de trabalho, aos benefícios adicionais com os quais os empregados são contemplados, aos critérios de contratação, à eliminação das práticas discriminatórias no espaço das empresas, à relação com sindicatos e associações de classe, ao desenvolvimento profissional dos empregados e ao acesso à informação que as empresas podem proporcionar a seus empregados. O indicador número seis assim interpela o empresariado:

(17MI) - Além de cumprir as obrigações determinadas por lei, a empresa se preocupa em oferecer a seus empregados um ambiente físico agradável e seguro, busca incentivar os cuidados com higiene e saúde e está aberta a críticas e sugestões relativas a esses aspectos? (SEBRAE; INSTITUTO ETHOS, 2012, p. 21, grifo nosso).

Embora a pergunta inicial faça referência ao processo dialógico entre empregadores e empregados quanto às condições de trabalho, nas perguntas subsequentes não são focalizados os meios pelos quais é possível instituir esse processo dialógico:

(18MI) - A empresa:

aboliu o fumo nos locais de trabalho?

incentiva os empregados a praticar atividades físicas?

orienta os empregados quanto aos cuidados com a postura corporal durante as atividades profissionais?

oferece instalações em boas condições de uso?

fornece equipamento de proteção individual (EPI), como óculos, capacete e protetor auditivo? 
orienta e incentiva o uso de EPI? (SEBRAE; INSTITUTO ETHOS, 2012, p. 21).

Retomando-se as informações do manual sobre a estrutura do questionário que indicam que as perguntas subsequentes à pergunta inicial "contêm elementos de validação e aprofundamento sobre o tema e contribuem para a compreensão de quais práticas devem ser incorporadas à gestão dos negócios" (SEBRAE; INSTITUTO ETHOS, 2012, p. 9) e ainda reconhecendo-se que uma gestão colaborativa entre empregadores e empregados, embora seja um cenário reconhecidamente desejável na literatura da área de atuação empresarial, não tem sido efetivada nas práticas cotidianas de trabalho, chama a atenção o fato de que na estrutura do manual não se oriente o micro e pequeno empresariado a refletir sobre os canais de comunicação que precisam ser estabelecidos nas empresas e sobre as atitudes que devem assumir os sujeitos do trabalho em relação a eles. Silenciar sobre as possíveis formas de estabelecer canais de comunicação eficientes na troca entre empregadores e empregados pode ser entendido como uma maneira de retardar, ou mesmo impedir, que uma relação dialógica entre os sujeitos de trabalho se efetive, uma vez que a mudança desse contexto dificilmente acontecerá espontaneamente.

No indicador referente às relações que se estabelecem entre as empresas e os sindicatos e as associações de classe, também é possível verificar que uma postura colaborativa é traduzida em termos de uma relação descendente da empresa para seus empregados e respectivos representantes:

(19MI) - Como forma de demonstrar respeito ao indivíduo e transparência em suas relações com o público interno, a empresa entende que é direito do funcionário participar de sindicatos e associações de classe e permite que representantes sindicais compareçam à empresa para discutir questões referentes aos interesses dos empregados? (SEBRAE; INSTITUTO ETHOS, 2012, p. 26).

(20MI) - A empresa disponibiliza aos empregados informações básicas sobre direitos e deveres da categoria, tais como dissídio, contribuições sindicais etc.? (SEBRAE; INSTITUTO ETHOS, 2012, p. 26).

Verbos como "permitir" e "disponibilizar" situam a empresa em um lugar de poder em relação a seus funcionários. O modo de dispor-se ao diálogo é traduzido por meio de enunciados que evocam uma relação hierárquica na qual as empresas abrem espaço para as questões de interesse dos empregados. Também verifica-se que os enunciados não traduzem com maior clareza a disposição das empresas para o diálogo sobre os temas relacionados às reinvindicações dos empregados quanto às condições de trabalho, mas a boa vontade em autorizar que esses temas circulem nos espaços de trabalho. Novamente reconhece-se o silenciamento sobre as formas de diálogo que caracterizariam uma gestão mais colaborativa e solidária.

\section{Considerações finais}

Considera-se que os dados reunidos e analisados neste artigo reforçam a convicção de que a relevância de se investigar os discursos prescritos em práticas de trabalho justifica-se em razão de se reconhecer que as práticas discursivas nesse campo não são apenas reflexos de uma realidade constituída a priori, mas são também processos de refração dessa realidade por 
diferentes sujeitos que se situam em diferentes lugares nesses espaços de trabalho. Reconhece-se, então, que o exercício linguageiro no âmbito do trabalho é um processo de constituição de realidades, de identidades e de relações sociais:

Na Linguística, por sua vez, os pesquisadores que se inserem no espaço em que se pensa a linguagem em ambientes de trabalho buscam encontrar os embasamentos teóricos e metodológicos que permitam o desvelamento do funcionamento linguístico-discursivo articulado ao contexto do trabalho. Esse tem sido um processo difícil, mas constante, o que tem gerado resultados ainda pouco visíveis, no entanto, relevantes para a compreensão das atividades de linguagem em relação ao contexto acional que as constitui e por elas é também constituído, bem como para a compreensão das atividades de trabalho na dimensão do processo de intercompreensão (e interincompreensão) que elas demandam e na dimensão do processo de constituição de objetos e de sujeitos do trabalho. (PESSOA; JOUBERT, 2012, p. 171).

A pesquisa sobre o discurso da RSE insere-se nesse contexto de investigação, questionando conceitos que tendem a se cristalizar sobre a contribuição das empresas para a solução de problemas sociais que são gerados, e permanentemente intensificados, pelo próprio sistema capitalista de exclusão a que as empresas pertencem. Questionam-se as noções de responsabilidade social e de solidariedade mobilizadas em uma prática pedagógica para formatar um determinado comportamento nos espaços de trabalho na tentativa de dissolver conflitos históricos por meio de ações consideradas positivas na perspectiva da comunidade discursiva empresarial. No entanto, a análise do funcionamento discursivo que se vislumbra através do texto delineia uma tentativa da comunidade empresarial frear as consequências indesejáveis advindas desses conflitos, ao se constituir uma cena de enunciação em que se pretende silenciá-los.

Esse silenciamento, todavia, não consegue ser absoluto, e na e pela materialidade dos enunciados é possível reencontrar a tensão latente entre formações discursivas que polemizam. A FD da solidariedade se choca com a FD da competitividade na prática discursiva empresarial sobre a RSE, uma vez que o lugar reservado ao outro nesse espaço discursivo é racionalizado pelas práticas que circunscrevem as ações que cabem a esse outro. Essas práticas não superam uma relação hierárquica entre os sujeitos do trabalho, em que os objetivos e interesses do eu sobrepõem-se aos do outro. A noção de solidariedade introduz-se no discurso da RSE na forma de um simulacro, na medida em que trazer o outro para o centro do discurso da competitividade começa a se estabelecer como uma forma de a comunidade discursiva empresarial controlá-lo.

No discurso da RSE empreende-se um esforço para articular novos conceitos a práticas de dominação históricas, dando-se visibilidade a uma cena enunciativa de equidade social, de ética nas relações de trabalho, de transparência nas ações de uma empresa, de uma postura dialógica entre os sujeitos que dividem o espaço de trabalho, de ocupação do espaço do Estado no atendimento às necessidades da comunidade externa no entorno das empresas. Mas tal articulação constitui-se como um mecanismo de conformação dos sujeitos exteriores à comunidade discursiva empresarial aos modelos impostos nas e pelas práticas discursivas dessa comunidade, para que as condições de produção e de lucratividade das corporações não sejam ameaçadas.

\section{REFERÊNCIAS}

Disponível em: http://seer.fclar.unesp.br/casa 
BRONCKART, J. P. Atividade de linguagem, textos e discursos: por um interacionismo sócio-discursivo. São Paulo: EDUC, 1999.

CESAR, M. de J. "Empresa-cidadã": uma estratégia de hegemonia. São Paulo: Cortez, 2008.

CHARAUdeaU, P.; MAInGUEnEAU, D. Dicionário de Análise do Discurso. 3. ed., São Paulo: Contexto, 2012.

MAIngueneaU, D. Novas Tendências em Análise do Discurso. 3 ed. Campinas, SP: Pontes: Editora da Universidade Estadual de Campinas, 1997.

Gênese dos discursos. São Paulo: Parábola Editorial, 2008.

PESSOA, F. C. da C.; JOUBERT, P. de C. A prática discursiva no contexto empresarial: a produção de um informativo organizacional. Revista Desenredo, Revista do Programa de Pós-Graduação em Letras da Universidade de Passo Fundo. v. 8, n. 1, jan - jun 2012, p. 170 192.

SAINSAULIEU, R.; KIRSCH, A. M. Sociologia da empresa: organização, poder, cultura e desenvolvimento no Brasil. Rio de Janeiro: DP\&A, 2006.

SERVIÇO BRASILEIRO DE APOIO ÀS MICRO E PEQUENAS EMPRESAS; INSTITUTO ETHOS DE EMPRESAS E RESPONSABILIDADE SOCIAL. Responsabilidade Social Empresarial para Micro e Pequenas Empresas - Passo a Passo. São Paulo: Sebrae /Instituto Ethos, 2003. Disponível em: http://www.uniethos.org.br/_Uniethos/Documents/responsabilidade_micro_empresas_passo.p df. Acesso em: 19 nov. 2012.

Indicadores Ethos-Sebrae de Responsabilidade Social Empresarial para Micro e Pequenas Empresas. São Paulo: Sebrae /Instituto Ethos, 2012. 